\title{
Best Practices in
}

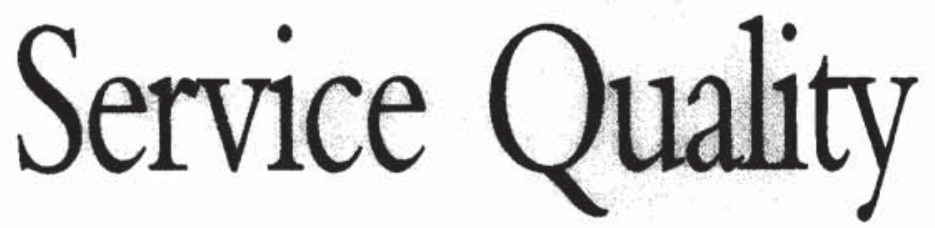

by Cathy A. Enz and Judy A. Siguaw

To achieve the highest service quality, managers of a baker's dozen of lodging

operations have given authority to their employees.

rom 1998 to 1999 , researchers affiliated with the Cornell University School of Hotel Administration conducted a comprehensive study of the best practices in the U.S. lodging industry. Many of the innovative firms featured in this study were found to share a common commitment to guest service. ${ }^{1}$ In this article we examine 13 champions that have excelled in enhancing service to the customer through various initiatives. We classify these champions into four categories: (1) creating a service culture, (2) building an empowered service-delivery system, (3) facilitating a "customer listening" orientation, and (4) developing responsive service guarantees.

In this article we review and describe those champions that, having recognized that the customer's evaluation of quality is often determined during the service encounter, have fostered a strong service cul-

${ }^{1}$ The full study is available in: Laurette Dubé, Cathy A. Enz, Leo M. Renaghan, and Judy A. Siguaw, American Lodging Excellence: The Key to Best Practices in the U.S. Lodging Industry (Washington, DC: American Express and the American Hotel Foundation, 1999). ture by focusing on training, developing, and empowering service personnel. We then explore a second area of excellence in which the champions provide a guarantee or promise of service delivery to the customer. Next, we describe the benefits accrued to those champions that have developed a strong commitment to service. The paper concludes with insights and advice from these service-quality champions for those who might wish to incorporate the ideas discussed here into their own operations. Exhibit 1 provides an overview of the service-quality champions and how they evaluated the success of their practices, while Exhibit 2

Cathy A. Enz, Ph.D., is the executive director of the Center for Hospitality Research and the Lewis G. Schaeneman, Jr., Professor of Innovation and Dynamic Management at the Cornell University School of Hotel Administration "cae4@ cornell.edu", where Judy A. Siguaw, D.B.A., is an associate professor of marketing "jas92@cornell.edu».

(c) 2000, Cornell University 


\section{EXHIBIT 1}

\section{Overview of service-quality best-practice champions}

\author{
Service-quality champion \\ Ashley House Hotels- \\ Keswick Hall \\ Practice initiated, developed \\ A service-quality training and orientation pro- \\ gram, including employees' becoming \\ guests to understand the experience.
}

\section{Measures of success}

Decreased employee turnover.

\begin{tabular}{|c|c|c|}
\hline The Boulders & $\begin{array}{l}\text { The development of a service culture through } \\
10 \text { principles, coaching, rewards, and } \\
\text { training. }\end{array}$ & $\begin{array}{l}\text { Decreased employee turnover; winner of Andrew } \\
\text { Harper Award for superior guest service. }\end{array}$ \\
\hline
\end{tabular}

Carlson Hospitality Worldwide A total-customer-satisfaction program with employee empowerment and a chain-wide,

Increase in ADR, occupancy rate, market share, and customer retention. interactive, on-line database.

Cincinnati Marriott Northeast An integrated guest service program based on 12 points.

Four-time winner of top Marriott award in less than two years; number-one rating for guest satisfaction; high levels of employee satisfaction.

\begin{tabular}{llcl} 
Club Hotel by Doubletree & $\begin{array}{c}\text { The establishment of CARE committees for } \\
\text { guest relations and employee relations. }\end{array}$ & $\begin{array}{c}\text { Increase in employee satisfaction; reduced employ } \\
\text { turnover. }\end{array}$ \\
\hline Dahlman Properties & $\begin{array}{r}\text { A seven-point action plan designed and devel- } \\
\text { oped to enhance the service environment. }\end{array}$ & $\begin{array}{c}\text { Positive work environment; reduced employee } \\
\text { turnover. Improved guest services; high level } \\
\text { of guest satisfaction. }\end{array}$
\end{tabular}

\section{Four Seasons \& Regent Hotels \& Resorts \\ Developing and maintaining a service-oriented culture through a high ratio of employees to guests.}

The Inn at Essex
An empowered workforce that never says no to a guest request.
High levels of chain growth and profitability; routinely listed as one of the 100 best companies for which to work.
Long tenure as four-star hotel; high employee satisfaction and retention rates; high customer retention.

\section{Promus Hotel Corporation A guarantee of 100-percent guest satisfaction. Return intentions for guests exceed all expectations.}

\section{Ritz-Carlton Hotel Company \\ Careful selection, training, and empowerment of employees to maximize guest service.}

Reduction in midlevel supervisory personnel; reduced employee turnover; increased customer loyalty and RevPAR.

The Waldorf=Astoria $\quad \begin{aligned} & \text { Gathering customer feedback via a quality } \\ & \text { quiz and using the information to improve } \\ & \text { employee performance. }\end{aligned}$
employee performance.
Increased customer satisfaction and room rate; named one of top-25 luxury hotels.

\begin{tabular}{lll} 
Windsor Court Hotel & $\begin{array}{c}\text { A strong guest-recognition and employee- } \\
\text { empowerment program. }\end{array}$ & $\begin{array}{c}\text { Rated number-one hotel in world by Condé Nast } \\
\text { Traveler. }\end{array}$ \\
\hline Winegardner \& Hammons & $\begin{array}{c}\text { The development of a comprehensive } \\
\text { pre-opening handbook. }\end{array}$ & $\begin{array}{c}\text { High levels of guest satisfaction during openings; } \\
\text { openings remain within budget and on time. }\end{array}$
\end{tabular}




\section{Exhibit 2 \\ Service-quality (SQ) best-practices cases, descriptions, implementation, and contact people}

\section{SQ champion, title of case

\begin{tabular}{l}
\hline Ashley House Hotels- \\
Keswick Hall \\
Quality-service- \\
management \\
Program for \\
Employees
\end{tabular}

\begin{tabular}{|c|c|}
\hline The Boulders & Created a vision of excellent guest \\
\hline $\begin{array}{l}\text { Cornerstone Program: } \\
\text { Developing a } \\
\text { Service Culture }\end{array}$ & $\begin{array}{l}\text { employee recognition are all ele- } \\
\text { ments of the program. }\end{array}$ \\
\hline
\end{tabular}

Carlson Hospitality Instituted a customer-satisfaction
Worldwide policy in which employees are

Total Customer Satisfaction via an On-line Database and Employee Empowerment empowered to handle customer complaints. Is currently developing a chain-wide, interactive on-line database of customer information.

\begin{abstract}
Method of implementation
Each employee is designated "Captain Quality" for a week. This role involves being a guest and visiting each department. Training on communication and atmospherics (e.g., noise, lighting) are employed during the year.
\end{abstract}

Owners and managers created the vision and the principles. Managers were selected to be coaches. Coaches were trained, and now must try out to fill vacancies.

Conducted research on guarantees, including focus groups with guests, employees, and operators. Developed training materials and programs. Pilot tested at 28 Radisson hotels and obtained positive results. Launched program globally in 1998.

Cincinnati Marriott Northeast

Treating the Guest as Part of the Family

\author{
Developed a 12-point guest- \\ service program with pledge \\ cards, pep rallies and staff- \\ recognition programs.
}

\section{The general manager reintroduced the}

12-point guest service program originally developed by the opening team. Daily meetings and other gatherings reinforce and emphasize the guest service points.
Contact person

Stephen Beaumont, general manager

804-923-4340

Fax: 804-977-4171

Judy Dewey, director of human resources

602-488-9009

Fax: $602-488-7302$

Curtis Nelson, president and CEO

612-449-1323

Fax: $612-449-1241$

\section{Kent Bruggeman, general manager}

513-459-9800 Fax: $513-459-9808$

Continued on next page

Note: The case titles correspond to the cases written on each champion in: Laurette Dubé, Cathy A. Enz, Leo M. Renaghan, and Judy A. Siguaw, American Lodging Excellence: The Key to Best Practices in the U.S. Lodging Industry (Washington, D.C.: American Express and the American Hotel Foundation, 1999).

describes the practices and offers the name and telephone number of a contact person. ${ }^{2}$

\footnotetext{
${ }^{2}$ Similar data on additional best practices is available as follows: Judy A. Siguaw and Cathy $\mathrm{A}$. Enz, "Best Practices in Marketing," Cornell Hotel and Restaurant Administration Quarterly, Vol. 40, No. 5 (October 1999), pp. 31-43; Judy A. Siguaw and Cathy A. Enz, "Best Practices in Hotel Architecture," Comell Hotel and Restaurant Administration Quarterly, Vol. 40, No. 5 (October 1999), pp. 44-49; Judy A. Siguaw and Cathy A. Enz, "Best Practices in Food and Beverage Management," Cornell Hotel and Restaurant Administration Quarterly, Vol.40, No. 5 (October 1999), pp. 5057; Judy A. Siguaw and Cathy A. Enz, "Best Practices in Information Technology," Cornell Hotel and Restaurant Administration Quarterly, Vol. 40, No. 5 (October 1999), pp. 58-71; Judy A. Siguaw and Cathy A. Enz,"Best Practices in Hotel Operations," Cornell Hotel and Restaurant Administration Quarterly, Vol. 40, No.6 (December 1999), pp. 42-52; and Cathy A. Enz and Judy A. Siguaw, "Best Practices in Human Resources," Cornell Hotel and Restaurant Administration Quarterly, Vol.41, No. 1 (February 2000), pp. 48-61.
}

\section{Committing to Guest Service}

The service-quality champions employed a variety of approaches, frequently in combination. Some of the champions, for example, worked on weaving key tenets into the fabric of the organization in an effort to disseminate service-excellence standards and ingrain employees with them. Others focused on empowering employees to provide whatever service the employee deemed necessary to create guest satisfaction. Still other champions developed comprehensive, but readily understandable methods for collecting and generating information concerning customer wants and needs. Finally, a few champions implemented customer-satisfaction guarantees. In the following sec- tions, we provide details concerning the practices of the following service-quality champions. They are Ashley House Hotels-Keswick Hall, the Boulders Resort, Carlson Hospitality Worldwide, Cincinnati Marriott Northeast, Club Hotel by Doubletree, Dahlman Properties, Four Seasons \& Regent Hotels \& Resorts, the Inn at Essex, Promus Hotel Corporation, Ritz-Carlton Hotel Company, the Waldorf= Astoria, Windsor Court Hotel, and Winegardner \& Hammons Incorporated.

\section{Principle-driven Service Orientations}

Four of the 13 champions-namely, the Boulders, Cincinnati Marriott Northeast, Four Seasons \& Regent, and Ritz-Carlton-developed 
Exhibit 2, continued from previous page

\section{SQ champion, title of case \\ Club Hotel by Doubletree \\ Employee-care \\ Committees \\ Description of case \\ Established a CARE committee with two subcommittees-one for guest relations, the other for employee relations.}

Method of implementation

Human-resources department seeks charter members of the Employee Care Committees.

\section{Contact person}

Toni Spiziri, humanresources manager

847-296-8866

Fax: 847-296-7999

Andy Dahlman, director of acquisitions

734-761-7600

Fax: 734-761-9178 action plan. A trial was initially conducted in one department of one hotel.

A benchmarking study was the first stage of this practice. A development variety of initiatives to enhance environment.

\section{Four Seasons \& Regent Maintain a service-oriented culture Hotels \& Resorts \\ Developing a High Ratio of Employees to Guests guests, along with careful selection and orientation.}

This practice stems from the beliefs and principles established by company founder Isadore Sharp. These tenets are sustained via the Four Seasons culture.

Barbara Talbott, exec. VP, marketing

\section{Accommodates all guest requests} built on a philosophy of never saying no. casual uniforms, no job descriptions, promotion from within, employee
416-441-4395

Fax: 416-441-4414
Uses a one-page policy manual, rewards, and an exchange program with other New England hotels to support employees as they accommodate guest requests.

First, research was conducted on guaranteed satisfaction. Afterward, employees and guests were asked to evaluate the proposal. A 12-month trial program in several hotels established the viability of the practice. The guarantee was put in place systemwide in 1989.

\begin{tabular}{ll}
\hline The Ritz-Carlton Hotel & $\begin{array}{c}\text { Ensures superior customer service } \\
\text { Using selection and training based }\end{array}$ \\
Company & on a set of principles.
\end{tabular}
Service

The basic concept of customer service is developed at the corporate level and then implemented at the property level through careful selection, seminars, project teams, and employee empowerment.

\begin{tabular}{|c|c|}
\hline $\begin{array}{l}\text { The Waldorf=Astoria } \\
\text { Gathering Customer } \\
\text { Feedback and Cod- } \\
\text { ing Performance }\end{array}$ & $\begin{array}{l}\text { Determines ways to improve opera- } \\
\text { tions with a quality quiz given to } \\
\text { guests at every service contact poi } \\
\text { and track results with a coding } \\
\text { scheme. }\end{array}$ \\
\hline $\begin{array}{l}\text { Windsor Court Hotel } \\
\text { Sophisticated Guest- } \\
\text { recognition Program }\end{array}$ & $\begin{array}{l}\text { Maintains guest-recognition and } \\
\text { employee-empowerment programs }\end{array}$ \\
\hline $\begin{array}{l}\text { Winegardner \& } \\
\text { Hammons Inc. } \\
\text { Pre-opening Handbook } \\
\text { for New Hotel } \\
\text { Properties }\end{array}$ & $\begin{array}{l}\text { Developed a comprehensive hand- } \\
\text { book to guide hotel openings and } \\
\text { set service standards, covering } 35 \\
\text { areas from the cost of small wares } \\
\text { to stafting levels. }\end{array}$ \\
\hline
\end{tabular}

Hilton, in partnership with J.D. Power, developed a 30-second quality quiz. summaries that indicate to employees how they are doing.

\section{Every employee has the authority to} act on guest issues. Repeat customers are provided special greetings and gifts. The results are placed in month-end
This practice evolved over a 12-year period. Senior managers consolidated and expanded previous preopening manuals into one comprehensive handbook.
Jim Hartigan, senior director, quality assurance and guest satisfaction

901-374-5998 Fax: 901-374-5976
Jim Lamberti, owner-manager

802-764-1432 Fax: 802-878-0063
Patrick Mene, vice president of quality

404-237-5500

Fax: 404-261-0119
Eric Long, general manager

212-355-3000 Fax: $212-371-3510$

Hansjörg Maissen, managing director

504-598-4780 Fax: 504-596-4754

Dennis Lanners, vice president of $F \& B$

513-891-1066 Fax: 513-794-2590 


\section{Exhibit 3 \\ Two operations' guiding principles}

Note the similarities between the independently developed guiding

principles of two disparate hotels.

The Boulders: 10 "cornerstone" principles

(1) Awareness of the Zone (that is, when a guest is within five feet of you, make eye contact, speak first, smile, and use the guest's name).

(2) Owning guests' requests

(3) Fiscal responsibility

(4) Ambassador

(5) Image

(6) Phone etiquette

(7) Cleanliness

(8) Respecting priorities

(9) Personalizing the experience

(10) Having fun
Cincinnati Marriott Northeast: 12-point program

(1) Address each guest by name, if possible.

(2) Establish eye contact with a guest who is within 20 feet.

(3) Smile at a guest who is within 10 feet.

(4) Answer a guest with "it is my pleasure," rather than "you're welcome."

(5) Escort guests to their destination each time, rather than just pointing the way.

(6) When a guest asks something of the employee, the employee should realize that he or she owns the request, rather than giving the request to some other employee.

(7) Concentrate on what an employee will be "happy to do," rather than what the employee "can't do."

(8) Always answer the phone on four rings or fewer.

(9) Notify the department head of any accident.

(10) Always wear the proper uniform and name tag, maintain a shoeshine, and carry the 12-pointpledge card.

(11) Arrive when scheduled and on time.

(12) Always show respect for other employees and work closely with them.

values and principles to facilitate the creation of service cultures. "Seek opportunities to create memories" is the vision statement that guides the Boulders, a luxury property located in Carefree, Arizona. To fulfill this vision and deliver on excellent guest service the resort's owners and managers created ten cornerstones (see Exhibit 3), which are basic concepts that apply to both external guests and "internal guests" (i.e., employees). ${ }^{3}$ To help communicate these principles to employees, 15 managers were originally selected to be "cornerstone coaches." The program was introduced to employees one cornerstone at a time in 15-

\footnotetext{
${ }^{3}$ This project was completed before the Boulders was purchased by Patriot American Hospitality, now know as Wyndham Hotels.
}

minute sessions. This process of explaining and embedding the ten cornerstones took a year, although "cornerstone training" is ongoing. The coaches selected for cornerstone training are dedicated longterm employees who devote a great deal of time in preparation for training. Coaches also have weekly planning sessions called the coaches' huddle, and have assembled manuals known collectively as "Focus." Employee-recognition programs, such as "Brag," are instrumental in recognizing and celebrating employees who do a particularly good job in carrying out the cornerstones.

Enduring value. For Four Seasons \& Regent Hotels \& Resorts, a key belief is a deeply instilled ethic of personal service. The company pursues its standards relentlessly, building on a foundation of offering only experiences of exceptional quality and properties of enduring value. ${ }^{4}$ To achieve its service commitments, the company maintains a high ratio of employees to guests. New employees are given an intensive orientation in the basics of the Four Seasons philosophy and culture. Each new employee is interviewed by top managers and then participates in a seven-part orientation program spread over 12 weeks. The training process culminates with an overnight stay in the hotel, which allows the new hire to experience all aspects of service just as a guest would. Both formal and informal mentoring relationships are also developed.

Other actions that support the high service standards include careful employee selection, ongoing training, executive site visits, inspections, meetings, and promotion from within. A committee of senior managers reviews the operating standards quarterly using information from focus groups, guests, and general managers. Four Seasons's devotion to service excellence is demonstrated through clear and exacting standards, close attention to selecting and preparing its employees in service, and accepting no compromises to quality.

Family matters. The general manager of the Cincinnati Marriott Northeast implemented a 12-point service program designed to encourage staff members to treat each guest as though she or he was "part of the family and on a visit to your home." This philosophy of treating the customer as part of the family, originally advocated by J.W. Marriott, Jr., was the foundation for re-

\footnotetext{
${ }^{4}$ For a description of the Four Seasons policies, see: Jeffrey Catrett and Michael Lynn, "Managing Status in the Hotel Industry: How Four Seasons Came to the Fore," Cornell Hotel and Restaurant Administration Quarterly, Vol. 40, No. 1(February 1999), pp. 26-39.
} 
energizing this hotel's guest-service focus. The 12-point program (see Exhibit 3) was developed by Winegardner and Hammons during pre-opening activities, but had begun to wane after the first five months of operation. To revive the principles and philosophy, the GM required employees to carry pledge cards, and each daily meeting begins with a review of the importance of satisfying the guest. Every Friday afternoon all employees and any guests who so desire gather on the lobby terrace for a pep rally during which guest letters and cards are read. The associates yell the hotel's special cheer during the rally, helping to heighten the loyalty of the staff and create a spirit of family among all who attend. Finally, to help sustain commitment to the 12 points, the GM has instituted a number of staff-recognition programs for exceptional guest service, including rewards for back-of-thehouse personnel.

Service credo. Ritz-Carlton is a classic example of a principles-based orientation to service. The credo, "Ladies and Gentlemen Serving Ladies and Gentlemen," espoused by president Horst Schulze when the Ritz-Carlton chain was started in 1983 , forms the basis for sophisticated methods of attaining high levels of guest service in all areas and departments of its hotels. ${ }^{5}$ Two keys to delivering on this philosophy are selecting (not merely hiring) the right people and constant reaffirmation of the Ritz-Carlton principles. The company hires only employees who share its values, as determined in a structured interview that is empirically scored. A series of receptions is also held for prospective employees to provide managers with an opportunity to

\footnotetext{
${ }^{5}$ See: William E. Kent, "Putting Up the Ritz: Using Culture to Open a Hotel," Cornell Hotel and Restaurant Administration Quarterly, Vol.31, No. 3 (November 1990), pp. 16-24.
}

observe the prospective hires in social situations and in face-to-face communications. Finally, in keeping with Deming's principles of management, project teams are created to determine operating methods, solve problems, and enhance customer service. $^{6}$

Experienced opening. Acknowledging that guests of new properties expect the same level of service and employee competency as that found in properties that have been operating for years, Winegardner and Hammons created a handbook that covers all pre-opening and opening phases of a property to ensure that employees can meet or exceed guests' expectations. That handbook synthesizes over a decade of experience in opening new properties and is constantly refined and updated for each new opening. Consequently, service standards are established immediately, and the handbook serves as documentation of the expected service culture.

\section{Developing Empowered Service Employees}

Delivering superior service is at the heart of many of our champions' best practices. Most of these companies rely directly on their employees for that superior service. RitzCarlton Hotels, for example, empowers all employees to spend up to $\$ 2,000$ to solve a guest problem, if need be. At the Inn at Essex, similarly, the approach is clear and simple: always say yes to the customer. The inn has no detailed policy manual and no list of dos and don'ts. Instead, Jim Lamberti, the owner-manager, distributes a onepage policy manual that has four points. Those are: (1) The hotel has had a four-star rating since its open-

\footnotetext{
${ }^{6}$ For example, see: W. Edwards Deming, Elementary Principles of Statistical Control: $A$ Series of Lectures (Tokyo: Nippon Kagato Gijutso Remmei, 1950).
}

Ritz-Carlton, for one, uses a

structured interview to hire

only those individuals who

share its values. 


\section{Exhibit 4 Dahlman Properties action plan}

(1) Develop the mission statement (three component parts)

(a) To provide outstanding guest services,

(b) To provide the finest service amenities, and

(c) To create superior individual employees.

(2) Develop a creed and the hotel basics (short version of the mission statement)

(3) Create a friendly work environment

(a) Consider the employees to be "internal" guests.

(b) Examine the current work environment and discuss ways it could be improved.

(c) Make employees feel like "part of the family."

(d) Take employee concerns seriously.

(e) Maintain an open-door management policy.

(f) Obtain support for this program from department heads.

(g) Post thank-you cards on the bulletin board when someone helps out in another department.

(h) Establish a "flash fund" to provide an immediate financial reward for an employee who does something exceptional.

(i) Establish a "Good Idea Board," the purpose of which is to track an idea so the employees do not feel that it has simply been disregarded. Tracking categories are:

(1) suggestion or recommendation,

(2) under study,

(3) pilot,

(4) implemented, and

(5) not implemented. (Before an idea comes off the board, there is an agreement between the author and the manager.)

Bonuses of $\$ 25$ are offered for the following idea categories:

(1) Improvement in guest services,

(2) Improvement in employee morale,

(3) Monetary savings, and

(4) Improvement in safety.

(j) Establish an empowerment program.

(k) Establish lateral service, so anyone can be asked to help another department at any time. Everyone should know at least one item in another department.

(l) Create teamwork.

(m) Develop exit interviews.

\section{(4) Improve the selection process}

(a) Incorporate a job-preview session where the applicant is observed working in a department for half a day prior to a final job offer.

(b) Hire only individuals who smile. It is impossible to train employees to smile.

(c) Verify that the interviewee understands the job description.

(d) Schedule exit interviews with terminated employees to understand what went wrong.

(5) Improve the company's training process

(a) Establish an orientation of each department during the initial week following the hire, so the individual will know a little about each department and the concept of "lateral service."

(b) Use quizzes and tests throughout the training period.

(c) Adhere to the training manual.

(d) Establish a half-day period during initial training for the new hire to study the company's philosophies (e.g., the mission statement).

(e) Create a 21-day training process that includes various meetings with department heads and, on the twenty-first day, a meeting with the general manager to ensure everything is moving in the proper direction.

(f) Use videos and handouts.

(g) Create an ongoing and continuing-education program.

(6) Create a team concept

- Emphasize that employees have been "selected" versus merely "hired."

(7) Improve guest services to the "external" guest ing in 1989; (2) Be proactively friendly; (3) Always find a way to say yes; and (4) When faced with a situation, if you make a decision for the benefit of the guest, 90 percent of the time you will be right, and management will back you 100 percent of the time.

To help reinforce this approach to service and to support employees, the inn also provides appropriate uniforms for the staff, promotes from within, provides no job descriptions, rewards employees, and enables employees to gain insight into other New England hotels through an exchange program of free employee stays. This approach is highly congruent with the methods used by some of the most innovative firms found in other industries. ${ }^{7}$

Guest recognition is combined with employee empowerment at the Windsor Court Hotel, which uses personal interaction built on strong guest feedback as the basis of service quality. All repeat guests are greeted at arrival and departure by either the managing director or one of two guest-relations managers, and are given small gifts that vary according to how frequently the guests have stayed in the hotel. To ensure continuous service-quality improvement, the hotel requests a recommendation for improvement from each guest at checkout. In addition, the front-office staff records any guest complaints on an incident form for immediate management follow-up via letter or telephone. Employees also have the authority to act on the spot to resolve a guest complaint, and any complaints are recorded for monthly evaluation. Finally, employees who exemplify the service

${ }^{7}$ See: Rosabeth Moss Kanter, The Change Masters: Innovation and Entrepreneurship in the American Corporation (New York: Simon \& Schuster, 1983). 
standards of the hotel are recognized in a "Kudos" reward program, in which employees receive giftshop merchandise. Other awards are given to employees monthly and annually.

The general manager of Ashley House Hotels-Keswich Hall developed a three-phase program to ensure that high-quality service complements a high-quality product. The first phase of the program, called "Captain Quality," is considered the most important of the three stages. Each of the hotel's 55 employees takes a turn as Captain Quality, an assignment made by lot that begins with a night as a guest of the hotel (including dinner for two). The employee then spends a week observing every department and submits a list of six points of needed improvement in the hotel. The points are posted and directed to the attention of the responsible department heads. The process then resumes the next week with a new Captain Quality.

The second phase of the Ashley House program is a semi-annual, day-long training program conducted by the general manager. This training emphasizes communication skills and the employees' responsibility to take the initiative to solve problems. The final phase alerts employees to the nuances that make up the atmosphere of the hotel, such as the noises, smells, lighting, and ambience necessary to produce a pleasant guest experience. Newemployee orientation and additional presentations several times a year are reserved for discussions and sharing of ideas on atmospherics.

Dahlman Properties developed a seven-part plan to reduce employee turnover and to obtain talented employees in a tight labor market. The plan was developed after Dahlman conducted a benchmarking study of Ritz-Carlton (see
Exhibit 4). The action plan includes a variety of different humanresources practices, including selection, training, empowerment, vision creation, and work-environment enhancements. One feature of the action plan was to improve the selection process via job-preview sessions during which the company observes job applicants working in a department for a half-day prior to extending a job offer. Throughout the recruitment process, the company places its emphasis on employees' being selected, rather than hired, a practice also used by Ritz-Carlton.

\section{Listening to Customers}

Several of our best-practice champions realize the importance of listening to their customers. Whether the feedback is a system of rating the hotel's performance (such as that used at the Waldorf= Astoria and throughout the Hilton system) or a collection of guestindex cards (such as those reviewed by the CARE committee at the Club Hotel by Doubletree), these quality-service champions are engaged in a dialogue with their customers to discover opportunities for improvement.

The Waldorf=Astoria, for instance, administers a "quality quiz" to guests at every service-contact point. In collaboration with J.D. Power, Hilton developed the 30second quality quiz comprising five or six questions to stimulate customer feedback. According to Eric Long, the general manager of the Waldorf $=$ Astoria, approximately 100 surveys are received and scored daily. A coding scheme tracks the results of the quiz and indicates any actions needed to improve operations. Month-end summaries are provided to hotel employees using an easy to understand red, yellow, and green zone system. Green is "good"; yellow is "you're making progress, but there is still work to do here"; and red is "we're really below the expected performance." The color scheme is so successful that the hotel has expanded it to encompass virtually all of the hotel's measurement devices. ${ }^{8}$ Long notes: "It is absolutely amazing to see the reaction when a particular team sees its performance is in the red zone. We could have the same score without the red designation and the team will be thoughtful. But add the red coloration, and it is like lightning."

Club CARE. Doubletree's Club Hotels established CARE committees to involve employees at all levels of the hotel operation in ensuring excellent guest service. Every department in the Club Hotel has a representative on the committee, and employees elect to serve on either the guest-relations or the employee-relations CARE committee. The employee-relations committee ensures service quality by auditing service standards, rewarding employees for outstanding service performance, encouraging and rewarding employees who generate innovative ideas, and maintaining high levels of employee morale.

The guest-relations committee monitors guest-comment cards to explore opportunities to improve guest services. The committee also selects a guest each month or quarter to be a mystery guest. This person stays at the hotel, uses all the facilities, and then grades the hotel's performance. In exchange the guest receives a free breakfast or a dis-

\footnotetext{
${ }^{8}$ For a more detailed discussion of Hilton's color scheme and related service-improvement mechanisms, see: Dieter Huckestein and Robert Duboff, "Hilton Hotels: A Comprehensive Approach to Delivering Value for All Stakeholders," Cornell Hotel and Restaurant Administration Quarterly, Vol. 40, No. 4 (August 1999), pp. 28-38.
} 


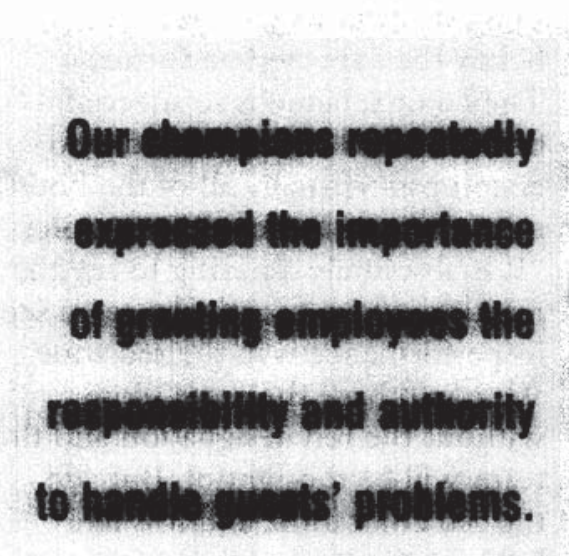

count on room charges. Other responsibilities of the guest-relations committee are to monitor the CARE HotLine (a system that records and responds to guests who phone the front desk to express dissatisfaction) and the CARE Repairs maintenance logs.

\section{Service Guarantees}

As a positioning strategy, service guarantees focus on producing enhanced customer loyalty. Two companies, Promus Hotels and Carlson Hospitality, are recognized as champions for their guarantees of 100 percent customer satisfaction. In 1989 Promus became the first hotel chain to institute such a policy. ${ }^{9}$ At any Promus hotel, the guest's stay is free if the guest is not completely satisfied for any reason. Furthermore, the hotel does not question the validity of any guest complaint, and employees are trained and empowered to immediately correct any problem the guest is experiencing. Guests are made aware of the satisfaction promise through promotion of the guarantee within the hotel and through print and broadcast media.

Carlson takes a slightly different approach to its guarantee. The guarantee of 100-percent customer satisfaction may be invoked when three conditions exist regarding the guest's complaint: (1) the guest perceives the problem as high in severity, (2) the guest perceives that the problem is the fault of the hotel, and (3) the hotel is unable to correct the problem in any other way that would satisfy the guest. Similar to Promus, Carlson employees are empowered to take the steps neces-

\footnotetext{
${ }^{9}$ For a discussion of the pros and cons of guarantee policies, see: Michael R. Evans and Bonnie J. Knutson, "The 100-Percent, Unconditional, Money-back Guarantee," Cornell Hotel and Restaurant Administration Quarterly, Vol. 37, No.6 (December 1996), pp. 56-61.
}

sary to satisfy the guest, including refunds. However, before they can administer the 100 -percent customer-satisfaction guarantee, hotel employees must participate in a two-stage training program. This training shows employees how to choose appropriate solutions to guest problems, explains the guarantee, empowers the employee, and outlines procedures for invoking the guarantee.

Although the guarantees offered by Promus and Carlson have been successful, the hotel industry as a whole has not embraced such guarantee policies. Nevertheless, we believe that service guarantees are valuable in attracting and retaining guests.

\section{Outcomes of a Commitment to Guest Service}

Placing the quality of guest service at the forefront of organizational concerns provides a variety of benefits to the hotel company. First, some champions (i.e., Ashley House Hotels-Keswick Hall, the Boulders, Club Hotel, Dahlman Properties, the Inn at Essex, and Ritz-Carlton) found that increased morale reduced employee turnover-even in tight labor markets. Second, the Boulders, Cincinnati Marriott Northeast, Dahlman Properties, Four Seasons \& Regent, and the Inn at Essex also noted intrinsic benefits accruing to their employees, such as increased pride, satisfaction, and camaraderie. Third, other champions (i.e., Carlson Hospitality, the Inn at Essex, Promus Hotels, Ritz-Carlton, the Waldorf $=$ Astoria, and Winegardner \& Hammons) reported enhanced performance measures, including increases in ADR, occupancies, market share, and customer-retention rates. Fourth, many champions-especially Carlson Hospitality Northeast, Dahlman Properties, the Waldorf= 
Astoria, and Winegardner \& Hammons-experienced positive guest feedback and improved customer satisfaction. Fifth, several firms won service-quality awards, including the Boulders, Cincinnati Marriott Northeast, Four Seasons \& Regent, the Waldorf $=$ Astoria, Windsor Court Hotel, and Winegardner \& Hammons. Finally, Ritz-Carlton noted that empowering employees permitted a $30-$ percent reduction in midlevel supervisory personnel.

\section{Insights}

These service-quality champions echoed a common theme. They emphasized the importance of getting employees involved early in the process (including during the selection or hiring process), rolling the program out gradually to gain employee support, and providing proper training and sufficient empowerment to allow employees to excel in their jobs. The champions also advised ensuring that top managers fully support, actively participate in, and reinforce the servicequality philosophy and program. Staff members must know that managers listen to the employees and support their actions.

A few champions, such as Carlson Hospitality, encouraged the use of a pilot program prior to embarking on a radically different service endeavor. The importance of a service commitment is perhaps best summed up by Kent Bruggeman, general manager of the Cincinnati Marriott Northeast, who stated: "Providing the guest with a superior experience is the only sustainable advantage that anybody has in our industry."

\section{Lessons}

Certainly no one within the hospitality industry denies the importance of setting and maintaining service standards. Moreover, as our champions demonstrate, a commitment to enhanced service levels can result in improvements in operating ratios and profitability. Yet, even with these proven benefits, relatively few hotels have successfully attempted to gain a competitive edge based on service quality.

Commitment to service. Given the complexities of the programs explained in this article, we believe that implementing such programs is difficult - and failure is a strong possibility. The following are the lessons of those programs. First, not only must a hotel elect to develop high standards of service quality, but its managers must adopt a true commitment to service. Many times senior managers of lodging organizations espouse a pledge to service, but are unwilling to support this vow through actions or resources. Thus, the "commitment" to service becomes only a hollow promise that employees and guests quickly recognize as worthless.

Empower all employees. Second, hotels must be willing to empower all employees. Our champions repeatedly expressed the importance of granting employees the responsibility and authority to handle guests' problems, but it seems that most hotel managers have difficulty relinquishing control to their staff members. We suggest, for example, that few hotel managers would be willing to allow their employees to spend $\$ 2,000$ to solve a guest problem, as does Ritz-Carlton, without attempting to oversee the transaction in some way. At the same time, some operations have difficulty empowering employees because of high turnover levels. Those firms will need to change their organizational culture to encourage employees to stay.
Evaluation standards. Finally, although our service champions did not expressly mention the way they evaluate employees, we contend that a commitment to service quality requires a revision in typical evaluation standards. If, for example, organizations continue to focus on cost reductions as a measure of job performance, the signal sent to employees is one that encourages scrimping on guest services and amenities, not one of satisfying guests' needs. Service quality, by contrast, consumes resources for training and rewarding employees who deliver service levels that exceed guest expectations. Thus, a commitment to service may actually incur increased expenses, even though profitability should also increase. Thus, employee-evaluation standards in a guest-service environment should focus on overall profitability, and not solely on costs. Otherwise, the establishment of a true commitment to service will not be facilitated.

As we close this final article in the series on the U.S. lodging industry's functional best practices, we encourage more hotels to take the critical step of committing to service excellence as an overriding goal. Not only is service a critical area for competitive differentiation, but our best-practices study indicated that the level of service quality is a key factor in determining customer satisfaction and overall customer loyalty, regardless of whether the customer was a leisure guest, business guest, or intermediary. Not only does a service-excellence focus allow for sustainable competitive advantage, but it is ethically appropriate, as Four Seasons expresses in its golden-rulebased credo. That is, every hotel employee should treat the guest the way the employee would wish to be treated. CQ 